have been $£ 20,000$ in the first year, rising to $£ 200,000$ by the fifth. Of the running cost of the institute, $£ 3$ million in the fifth year, one-third is to come from governments, one-third from private funds (like foundations) and the remaining third from fees from participants and their sponsors.

Despite the British Government's apparent indif- ference to the idea, no special barriers will be put in the way of British students wishing to attend the courses. In principle, at least, the fact that governments have supported the institute does not entitle them to more than their share of the places. Whether this ideal will be realized in practice is, of course, more open to doubt.

\title{
Apollo 8 and the View Beyond
}

\author{
from our Special Correspondent, Washington, December 10
}

T'He Acting Administrator of the National Aeronautics and Space Administration, Dr Thomas Paine, shows every sign of confidence that two Americans will tramp about on the surface of the Moon some time next year. The last flight of a team of three astronauts in October seems enormously to have cheered up those responsible for the Apollo programme. Even the accident this weekend which destroyed one of the machines being used to test the rocket system for descending the last few hundred feet to the surface of the Moon seems to have left them unmoved although, Dr Paine points out, in this business, as in the early days of aviation, an accident "is not serious if the people can walk away from it".

Plans are now well advanced for the journey around the Moon of the Apollo 8 spacecraft, now assembled at Cape Kennedy, due to begin some time during the week of December 21. After that, it may even be possible to decide precisely what test flights will be carried out before a descent to the surface of the Moon is attempted. The situation, in other words, is rather like that at the end of a long car journey when a driver may spend an unpredictable but still comparatively short time hunting about for his destination. There seems no danger that anything will go seriously awry and this suggests instead the analogy with the way in which Moses spent time hunting for the Promised Land.

Dr Paine looks back with mixed feelings over the interval since President Kennedy announced, in 1961, that there would be a serious attempt to send a man to the Moon "before this decade is out". Understandably, he is somewhat downcast that there are critics of the Moon programme even now that success is within sight. In a conversation yesterday he urged that the commitment to such a specific target was probably necessary in order to give the American taxpayer a feeling that his money was being well handled-a sign, said Dr Paine, of "Kennedy's genius for seeing all sides of the problem". In practice, he said, the commitment had turned out to be the only guarantee-people worked on the project as if they were impelled by the urgency of war. But the size of the programme had also made it possible to include within it several items of expenditure that would not otherwise have been possible-the support which the National Aeronautics and Space Administration has given to basic science, for example. If academic scientists were not satisfied with the support they had been given, this may be a sign, said Dr Paine, that they have not been sufficiently persuasive in putting their case. But in any case the outcome of the work now nearing completion in the
Apollo programme was the development of a technological tool which could be used for the rapid advance of science. The orbiting astronomical observatory, launched last week with great success, is one of the examples for which Dr Paine justly claims credit. In general, he said, it was mistaken to believe, as many people did, that if money had not been spent on getting to the Moon, it could promptly be diverted to other things. In any case, he said, the proposal that people should go to the Moon "within this decade" had been coupled with other proposals for development such as a commitment to develop networks of communications and meteorological satellites, for example-and these goals had already been attained.

But what of the future? Dr Paine agreed that the year ahead "is the year that really matters". The budget application which President Johnson will submit to Congress before he leaves office on January 20 and the response to it of the new Administration and of the new Congress will determine whether NASA remains a powerful agency or becomes just a shadow of its former self. Moreover, the decision will have to be made before American taxpayers have had a chance to see whether they have got full value for the $\$ 25$ thousand million which will have been spent on getting to the Moon. What Dr Paine would like to see is a budget of about $\$ 4$ thousand million, much the same as in the present year, and a fairly constant expenditure at that level until the budget would expand again five or six years from now.

Several objectives come quickly to Dr Paine. First, the agency would like to see some use made of the system which has been developed at such cost for launching the Apollo vehicles. What this means is that there should be at least two visits a year to the Moon and at some point, Dr Paine says, it would be necessary to build a shelter there. There is also great interest in schemes for using rocket systems in which the more expensive parts are reusable. The scheme for shuttling rockets in both directions between orbits around the Earth and the Moon is one which offers great advantages. But Dr Paine says that he is also anxious that the programme agreed by Congress for the period after July next year, the beginning of the new fiscal year, should include funds to enable the Administration to develop direct broadcasting communications satellites and surveillance systems for picking out the parts of the surface of the Earth with differing natural resources. Dr Paine also hopes that there will be money for scientific investigations of various kinds: journeys to the planets, of which the scheme to send a 
satellite out towards Pluto in 1978-79--when Jupiter and Saturn will be favourably aligned-is particularly attractive. On the relationship-sometimes the lack of a relationship-between NASA and the scientific community, Dr Paine considered that there may be some room for changing the administrative structure. One possibility would be to require that proposals for experiments should be publicly discussed among scientists before being considered by the Administration.

So far as the immediate future is concerned, however, everything is concentrated on the plan for Apollo 8 . For a detailed study of that shows how much substance there is in Dr Paine's assertion that there is plenty of room yet for development of the Apollo system. One apparently peripheral but potentially important development would be to increase the amount of storage in the computing system, which is at present $36 \mathrm{~K}$ of fixed storage with $2 \mathrm{~K}$ of erasable storage. Those responsible for the navigational planning of the enterprise point out that in future journeys, which are extremely complicated, it may be necessary to store on magnetic tape computer programs needed for carrying out individual steps in what may often be a complicated system of events. The lack of suitable storage is apparently a small defect but one which, no doubt, would not be remedied without some expense.

Perhaps the most impressive feature of the way in which the technology of space travelling has developed is the skill with which the group responsible for Apollo has been able to build a great deal of flexibility into the plan for Apollo 8. For one thing, this launching will differ from previous exercises in that the direction in which the rocket is aimed will vary with the time of launching. This is a consequence of the celestial mechanics of the exercise. The object is to find an orbit about the Earth which is parallel to the plane of the rotation of the Moon about the Earth. Given that the inclination of the axis of the Earth to this plane differs from a right angle, it is clear that the direction in which the rocket is injected into an Earth orbit must depend on the local time at the launching site. In practice, the need to avoid the risk of damage to heavily populated areas on the Earth requires that the direction of launch should lie between 72 degrees and 108 degrees. On each of the days, the week after next, on which launches are possible, there is a period of time (between 7.51 a.m. Eastern Standard Time and 12.32 p.m. Eastern Standard Time on December 21, for example) when a successful launch could be completed. At the beginning of this interval of time the launch would take place at 72 degrees--just north of east- and the aim would move progressively south during the five hours or so during which a successful launch is possible. The sequence of events on succeeding days is similar except that everything is retarded by about an hour and a half each day because of the motion of the Moon. Because the launch should ideally take place during daylight, it is unlikely that the exercise would be profitable once Christmas Day is past.

During the flight of the instruments to the Moon, there will be a complicated sequence of rocket firings at several of which it will be possible for the ground observers to decide that an alternative to travel round the Moon should be implemented. To begin with, the Apollo 8 spacecraft together with the third stage of the Saturn rocket will be parked in an orbit about the Earth at a height of 191 kilometres and inclined at 32.5 degrees to the Equator. The next step in the operation will be to change this orbit into one which is essentially a highly elliptical orbit about the Earth stretching out to the orbit of the Moon. The trick here is to ensure that the perigee of this orbit is correctly placed with respect to the position of the Moon at the time when the Apollo system may be expected to have reached the orbit of the Moon. The most disappointing outcome of this would be that the last stage of the rocket would burn inadequately, in which case the three astronauts travelling on Apollo 8 may have to reconcile themselves to spending ten days in orbit about the Earth. The possibilities that the velocity increase produced by the third stage of the Saturn motor may not be enough to carry Apollo 8 as far as the Moon have been catered for by proposals for modifying the orbit about the Earth-the system carries enough rocket power for that. The only difficulty seems to arise when by mischance the apogee of the elliptical orbit lies between 46,000 and 111,000 kilometres- then there will not be enough power to correct the orbit to one in which the radiation exposure will be comparatively moderate, in which case the spacecraft will have to return direct to the Earth.

On the way to the Moon, after the velocity has been increased to 10,900 metres a second, the spacecraft will be separated from the rocket after an interval of about 20 minutes and plans have been made for making sure that the spent rocket will pass behind the Moon and will then be accelerated into an orbit about the Sun. The spacecraft itself will be aimed ahead of the Moon which it will take roughly 66 hours to reach. Corrections to the velocity amounting to no more than a metre per second or thereabouts will be made, if necessary, at four points along the route. The intention is that the spacecraft will first be put in an orbit lying between 111 and 315 kilometres around the Moon, that it will be made a circular orbit at 111 kilometres after two revolutions and that the package as a whole will spend ten orbits (each of them roughly two hours) about the Moon before returning to the Earth. The elliptical orbit about the Moon has been chosen in such a way that the danger is minimized that small errors may cause the spacecraft to collide with the Moon.

A number of interesting navigational points have come to light. For one thing, it seems not yet to have been possible to determine precisely which horizon around the Earth is actually observed by astronauts operating from an orbit. Is it the solid Earth, the tropopause, or some other level in the atmosphere? One of the first tasks of the astronauts on the way to the Moon will be to make observations of the horizon which can then be calculated by means of ground-based observations of the position of Apollo 8. In its orbit about the Moon, the spacecraft will cover a narrow band within fifteen degrees north and south of the Equator. At its northernmost extremity, the orbit will lie just south of the Mare Imbrium. On all its ten orbits, Apollo 8 will pass directly above one of the landing sites chosen by unmanned observation of the Moon for a possible landing on some later journey. During its presence there, the three astronauts will be charged with carrying out an intensive programme of photography partly so as to collect a comprehensive stereoscopic panorama of a strip of terrain lying near the Equator of the Moon. 